\title{
Kinetic and Mechanistic Aspects of the Application of Diethyl Malonate as Proton Source during Protonation of Anion Radicals in $\mathbf{N}, \mathbf{N}$-Dimethylformamide
}

\author{
Merete Folmer Nielsen, Zeev Porat ${ }^{\star}$, Hanne Eggert and Ole Hammerich** \\ Department of General and Organic Chemistry, The H.C. Ørsted Institute, University of Copenhagen, \\ Universitetsparken 5, DK-2100 Copenhagen Ø, Denmark
}

\begin{abstract}
Nielsen, Merete Folmer, Porat, Zeev, Eggert, Hanne and Hammerich, Ole, 1986. Kinetic and Mechanistic Aspects of the Application of Diethyl Malonate as Proton Source during Protonation of Anion Radicals in $\mathrm{N}, \mathrm{N}$-Dimethylformamide. - Acta Chem. Scand. B 40: 652-656.

The application of derivative cyclic voltammetry to explore the mechanism of protonation of a number of anion radicals by diethyl malonate in $N, N$-dimethylformamide has demonstrated that the interconversion of the keto and enol forms of the carbon acid plays a dominant role in determining the kinetics. The formation of the enol form, which is the stronger acid, was shown to be effectively catalyzed by addition of base to the solvent system. The catalytic effect of base was strongly diminished in solvent containing water $(0.5 \mathrm{M})$.
\end{abstract}

The reactions between anion radicals, $\mathrm{A}^{-}$, derived from alternant aromatic hydrocarbons and proton donors, HB, are unique in the sense that the essential steps of the generally accepted mechanism only include the transfer of one electron or one proton (eqns. 1-4). The second electron transfer (eqn. 3) appears in general to be fast and strongly displaced in favor of the right hand side and, accordingly, the first proton transfer step (eqn. 2) becomes irreversible and rate determining. ${ }^{1-4}$

$$
\begin{aligned}
& \mathrm{A}+\mathrm{e}^{-} \rightleftharpoons \mathrm{A}^{-} \\
& \mathrm{A}^{-}+\mathrm{HB} \underset{k_{-2}}{\stackrel{k_{2}}{\rightleftharpoons}} \mathrm{AH}+\mathrm{B}^{-} \\
& \mathrm{AH}^{-}+\mathrm{A}^{-} \underset{k_{-3}}{\stackrel{k_{3}}{\rightleftharpoons}} \mathrm{AH}^{-}+\mathrm{A} \\
& \mathrm{AH}^{-}+\mathrm{HB} \stackrel{k_{4}}{\rightarrow} \mathrm{AH}_{2}+\mathrm{B}^{-}
\end{aligned}
$$

\footnotetext{
${ }^{*}$ Present address: Department of Materials Research, The Weizmann Institute of Science, Rehovot, Israel. ** To whom correspondence should be addressed.
}

Mechanistic studies of protonation of anion radicals in aprotic solvents have been made with a large variety of proton sources including water, aliphatic alcohols, phenols and substituted phenols as well as carboxylic acids and carbon acids. ${ }^{1,2,46}$ In the last group, the attention has been focused almost exclusively on diethyl malonate, ${ }^{7-19} \mathrm{H}_{2}$ DEM, the application of which in quantitative work gives rise to complicated rate laws as we will demonstrate.

\section{Results and discussion}

During investigations in this laboratory of the kinetic details of protonation of a number of anion radicals including those of phenazine, 2,4,6-triphenylpyrimidine, 1,4-diphenylphthalazine $\mathrm{N}$ oxide, ${ }^{18}$ naphthalene and a series of substituted naphthalenes, we have observed, contrary to our initial expectations, that the rate of disappearance of $\mathrm{A}^{-}$in the presence of $\mathrm{H}_{2} \mathrm{DEM}$ increased upon addition of base. The base, which was made from $\mathrm{Bu}_{4} \mathrm{NOH}$ and $\mathrm{H}_{2} \mathrm{DEM}$, was originally believed ${ }^{18}$ to be $\mathrm{Bu}_{4} \mathrm{~N}^{+}$, HDEM ${ }^{-}$. However, the anion of the salt has now been demonstrated to be $\mathrm{EtOOCCH}_{2} \mathrm{COO}^{-}$(see Experimental) and in the following we will refer to this anion as 
BASE $^{-}$. The accelerating effect is illustrated by the data obtained by derivative cyclic voltammetry, ${ }^{20} \mathrm{DCV}$, for the protonation of 2-methoxynaphthalene anion radical in $N, N$-dimethylformamide, DMF (Table 1). The value of $v_{0.8}$, the sweep rate necessary to keep the derivative peak current ratio equal to 0.8 , was observed to be equal to $7.3 \mathrm{~V} \cdot \mathrm{s}^{-1}$ for a solution which was $1 \mathrm{mM}$ in substrate and $64 \mathrm{mM}$ in $\mathrm{H}_{2} \mathrm{DEM}$. Addition of increasing amounts of $\mathrm{Bu}_{4} \mathrm{~N}^{+}$, BASE ${ }^{-}$to the voltammetric solution caused the value of $v_{0.8}$ to increase to more than $50 \mathrm{~V} \cdot \mathrm{s}^{-1}$ corresponding to an increase of the apparent protonation rate constant by a factor of 7 . A similar effect was observed for the other compounds mentioned above, but the magnitude of the acceleration was found to be dependent on the rate of disappearance of $\mathrm{A}^{-}$in the absence of $\mathrm{BASE}^{-}$.

Until now it has been tacitly assumed that the reactions indeed proceed according to the overall stoichiometry given in eqn. (5). However, it has been reported ${ }^{7}$ that the reaction between fluorene anion radical, $\mathrm{FL}^{-}$, and $\mathrm{H}_{2} \mathrm{DEM}$ apparently is not in agreement with eqn. (5), but rather involves reduction of the carbon acid resulting in formation of $\mathrm{H}_{2}$ and $\mathrm{HDEM}^{-}$and regeneration of FL (eqn. 6). These two reaction schemes can

$$
\begin{aligned}
& 2 \mathrm{~A}^{-}+2 \mathrm{H}_{2} \mathrm{DEM} \rightarrow \mathrm{AH}_{2}+\mathrm{A}+2 \mathrm{HDEM}^{-} \\
& 2 \mathrm{FL}^{-}+2 \mathrm{H}_{2} \mathrm{DEM} \rightarrow 2 \mathrm{FL}+\mathrm{H}_{2}+2 \mathrm{HDEM}^{-}
\end{aligned}
$$

Table 1. The effect of addition of BASE ${ }^{-}$on the rate of disappearance of 2-methoxynaphthalene anion radical in DMF and DMF/ $\mathrm{H}_{2} \mathrm{O}$ in the presence of $\mathrm{H}_{2} \mathrm{DEM}$.

\begin{tabular}{ccc}
\hline$C_{\mathrm{BASE}}^{\circ}-/ \mathrm{mM}$ & $v_{0.8}^{a} /\left(\mathrm{V} \cdot \mathrm{s}^{-1}\right)$ & $v_{0.8}^{b} /\left(\mathrm{V} \cdot \mathrm{s}^{-1}\right)$ \\
\hline 0 & 7.3 & 5.5 \\
1.8 & 12.9 & 8.5 \\
3.6 & 16.1 & 9.5 \\
6.2 & 22.0 & 9.8 \\
10.7 & 33.1 & 10.8 \\
17.8 & 46.4 & 12.3 \\
26.8 & 47.8 & 13.5 \\
40.1 & 53.1 & 13.4 \\
\hline
\end{tabular}

$C_{\mathrm{A}}^{\circ}=1 \mathrm{mM}, C_{\mathrm{H}_{2} \mathrm{DEM}}^{\circ}=64 \mathrm{mM}, C_{\mathrm{Bu}_{4} \mathrm{NBF}_{4}}^{\circ}=0.1 \mathrm{M}, E_{\mathrm{o}^{-}}$ $E_{\mathrm{sw}}=200 \mathrm{mV}, t=22^{\circ} \mathrm{C}$. ${ }^{a}$ Without addition of water. ${ }^{b} \mathrm{C}_{\mathrm{H}_{2} \mathrm{O}}^{\circ}=0.5 \mathrm{M}$. be distinguished by constant current coulometry. ${ }^{21}$ Under conditions where $C_{\mathrm{H}_{2} \text { DEM }}^{\mathrm{D}}$ is much larger than $C_{\mathrm{A}}^{\circ}$, the stoichiometry of eqn. (5) predicts that $2 \mathrm{~F} / \mathrm{mol}$ are required for the complete conversion of $\mathrm{A}$ to $\mathrm{AH}_{2}$, whereas eqn. (6), which describes an electrocatalytic reduction of $\mathrm{H}_{2}$ DEM, predicts that the amount of substrate in solution is left unaffected after the passage of this amount of charge. In the actual case, we have found that all the classes of compounds included in the study conform to eqn. (5) within experimental error and we conclude that the reaction accelerated by $\mathrm{BASE}^{-}$is indeed the protonation of $\mathrm{A}^{-}$with no appreciable contributions from other reaction pathways.

Diethyl malonate, owing its acidity to the presence of the two carbonyl groups adjacent to the central methylene unit, is expected to exist in solution in equilibrium with the tautomeric enol form, HDEMH (eqn. 7), like other compounds having the same structural feature. ${ }^{22-25}$ As a consequence of this, both the keto form, $\mathrm{H}_{2} \mathrm{DEM}$, and the enol form, HDEMH, can participate in the protonation of $\mathrm{A}^{-}$.

$\mathrm{H}_{2} \mathrm{DEM} \underset{k_{-7}}{\stackrel{k_{2}}{\rightleftharpoons}} \mathrm{HDEMH} \quad\left(K_{7}=k_{7} / k_{-7}\right)$

To the best of our knowledge, the value of $K_{7}$ has not been determined in DMF, but the application of ${ }^{1} \mathrm{H}$ and ${ }^{13} \mathrm{C}$ NMR spectroscopy shows that the equilibrium favors the keto form and has allowed us to estimate that $K_{7}$ is less than $2 \cdot 10^{-3}$. Now, since the enol form is expected to be a much stronger acid than the keto form, ${ }^{22-25}$ the acceleration of the protonation rate by addition of $\mathrm{BASE}^{-}$can be rationalized as being due to BASE $^{-}$catalysis of the formation of HDEMH (eqn. 8). At this point, it is important to notice that the concentration of basic species in solution is different from zero even in the cases where $\mathrm{BASE}^{-}$has not been added because the conjugate base, $\mathrm{HDEM}^{-}$, is produced during the protonation of $\mathrm{A}^{-}$by $\mathrm{H}_{2} \mathrm{DEM}$ or HDEMH. Since $\mathrm{HDEM}^{-}$can as well catalyze the enolization of $\mathrm{H}_{2}$ DEM (eqn. $8^{\prime}$ ), we have in the general case the set of proton and electron transfer steps represented by equations $8-13$. 
NIELSEN, PORAT, EGGERT AND HAMMERICH

$$
\begin{aligned}
& \mathrm{H}_{2} \mathrm{DEM}+\mathrm{BASE}^{-} \underset{k_{-8}}{\stackrel{k_{8}}{\rightleftharpoons}} \mathrm{HDEMH}_{\left(K_{8}=k_{8} / k_{-8}\right)} \mathrm{BASE}^{-} \\
& \mathrm{H}_{2} \mathrm{DEM}+\mathrm{HDEM}^{-} \stackrel{\frac{k_{8}^{\prime}}{\overrightarrow{k_{-8}^{\prime}}}}{\left.\mathrm{HDEMH}_{(}+\mathrm{HDEM}_{8}^{\prime}=k_{8}^{\prime} / k_{-8}^{\prime}\right)} \\
& \mathrm{A}^{-}+\mathrm{H}_{2} \mathrm{DEM} \stackrel{k_{9}}{\rightarrow} \mathrm{AH}^{-}+\mathrm{HDEM}^{-} \\
& \left(k_{10} \gg k_{9}\right) \\
& \mathrm{A}^{-}+\mathrm{HDEMH} \stackrel{k_{10}}{\rightarrow} \mathrm{AH}+\mathrm{HDEM}^{-} \\
& \mathrm{AH}+\mathrm{A}^{-} \stackrel{k_{11}}{\rightarrow} \mathrm{AH}^{-}+\mathrm{A} \\
& \mathrm{AH}^{-}+\mathrm{H}_{2} \mathrm{DEM} \stackrel{k_{12}}{\rightarrow} \mathrm{AH}_{2}+\mathrm{HDEM}^{-} \\
& \left(k_{13} \gg k_{12}\right) \\
& \mathrm{AH}^{-}+\mathrm{HDEMH} \stackrel{k_{13}}{\rightarrow} \mathrm{AH}_{2}+\mathrm{HDEM}^{-}
\end{aligned}
$$

Obviously, $K_{8}$ and $K_{8}^{\prime}$ are both equal to $K_{7}$. Under the assumption that the steady state approximation is valid for the three species $\mathrm{AH}, \mathrm{AH}^{-}$ and HDEMH and at the same time, that the ratio between the rate constants for protonation of $\mathrm{A}^{-}$ and $\mathrm{AH}^{-}$is independent of the nature of the acid, i.e. that $k_{9} / k_{12}=k_{10} / k_{13}$, we arrive at the general rate law for the reaction given in equation (14).

This rather complicated rate law may degenerate into one of two limiting cases depending on the competition between the two terms $k_{-8} C_{\mathrm{BASE}^{-}}^{\circ}+$ $k_{-8}^{\prime}\left[\mathrm{HDEM}^{-}\right]$and $2 k_{10}\left[\mathrm{~A}^{-}\right]$or, in other words, on the basicity of $\mathrm{A}^{-}$as reflected by $k_{10}$, since the term $k_{-8} C_{\mathrm{BASE}^{-}}^{\circ}+k_{-8}^{\prime}\left[\mathrm{HDEM}^{-}\right]$is independent of the nature of $\mathrm{A}$. When $k_{-8} C_{\mathrm{BASE}^{-}}^{\circ}+k_{-8}^{\prime}\left[\mathrm{HDEM}^{-}\right]$ $\gg 2 k_{10}\left[\mathrm{~A}^{-}\right]$and, at the same time, advantage is taken of the equality $k_{8} / k_{8}^{\prime}=k_{-8} / k_{-8}^{\prime}$, rate law (14) reduces to rate law (15). This situation corresponds to conditions where the interconversion of the keto and the enol forms can be regarded as a fast equilibrium prior to the rate determining proton transfer step. On the other hand, when $k_{-8} C_{\mathrm{BASE}^{-}}^{\circ}+k_{-8}^{\prime}\left[\mathrm{HDEM}^{-}\right] \ll 2 k_{10}\left[\mathrm{~A}^{-}\right]$, rate law
(14) reduces to rate law (16), which in the limit when $k_{\mathrm{s}} C_{\mathrm{BASE}^{-}}^{\mathrm{o}}+k_{\mathrm{8}}^{\prime}\left[\mathrm{HDEM}^{-}\right] \ll k_{\mathrm{g}}\left[\mathrm{A}^{-}\right]$, is further reduced to (17), corresponding to the direct proton transfer from the keto form to $\mathrm{A}^{-}$. Com-

$$
\begin{aligned}
& -\mathrm{d}\left[\mathrm{A}^{-}\right] / \mathrm{dt}=2\left(k_{9}+k_{10} K_{8}\right)\left[\mathrm{A}^{-}\right]\left[\mathrm{H}_{2} \mathrm{DEM}\right] \\
& -\mathrm{d}\left[\mathrm{A}^{-}\right] / \mathrm{d} t=2\left(k_{9}\left[\mathrm{~A}^{-}\right]\left[\mathrm{H}_{2} \mathrm{DEM}\right]+\left(k_{8} C_{\mathrm{BASE}^{-}}^{\circ}+\right.\right. \\
& \left.\left.k_{8}^{\prime}\left[\mathrm{HDEM}^{-}\right]\right)\left[\mathrm{H}_{2} \mathrm{DEM}\right]\right) \\
& -\mathrm{d}\left[\mathrm{A}^{-}\right] / \mathrm{d} t=2 k_{9}\left[\mathrm{~A}^{-}\right]\left[\mathrm{H}_{2} \mathrm{DEM}\right]
\end{aligned}
$$

parison of the four rate laws, (14)-(17), leads to the prediction that the acceleration by $\mathrm{BASE}^{-}$ depends on the basicity of $A^{-}$. For weakly basic $A^{-}$, the reaction follows rate law (15) and no effect of $\mathrm{BASE}^{-}$is expected. With increasing basicity of $\mathrm{A}^{-}$, the rate of disappearance of $\mathrm{A}^{-}$is successively described by rate laws (14), (16) and (17), predicting that the effect of $\mathrm{BASE}^{-}$passes through a maximum when $k_{-8} C_{\mathrm{BASE}^{-}}^{\circ}+$ $k_{-8}^{\prime}\left[\mathrm{HDEM}^{-}\right]$and $2 k_{10}\left[\mathrm{~A}^{-}\right]$are of comparable magnitude, after which, the effect decreases and finally vanishes completely (rate law (17)). These predictions were tested experimentally by varying the basicity of the naphthalene anion radicals by proper substitution, and the results are shown in Figure 1, which demonstrates the acceleration caused by $\mathrm{BASE}^{-}$measured as the ratio between the $v_{0.8}$ values at $C_{\mathrm{BASE}}^{\circ}$ equal to 10.7 and $1.8 \mathrm{mM}$. The lower concentration, $1.8 \mathrm{mM}$, was chosen instead of no addition of $\mathrm{BASE}^{-}$in order to minimize the influence of possible unknown basic species in the solution. The curve described by the experimental points is bell-shaped as predicted from rate laws (14)-(17), in support of the theoretical analysis. The catalytic effect of BASE $^{-}$most likely includes the following acidbase equilibria ${ }^{24}$ (eqn. 18):

$$
\begin{aligned}
& \mathrm{H}_{2} \mathrm{DEM}+\mathrm{BASE}^{-} \rightleftharpoons \mathrm{HDEM}^{-}+\mathrm{HBASE} \rightleftharpoons \\
& \mathrm{HDEMH}+\mathrm{BASE}^{-}
\end{aligned}
$$

Although the relative basicity of $\mathrm{BASE}^{-}$and HDEM $^{-}$, in general, does not affect the ratio between $\left[\mathrm{H}_{2} \mathrm{DEM}\right]$ and $[\mathrm{HDEMH}]$, the absolute

$-\mathrm{d}\left[\mathrm{A}^{-}\right] / \mathrm{d} t=2\left(k_{9}+k_{10} \frac{k_{8} C_{\mathrm{BASE}^{-}}^{\circ}+k_{8}^{\prime}\left[\mathrm{HDEM}^{-}\right]}{k_{-8} C_{\mathrm{BASE}^{-}}^{\circ}+k_{-8}^{\prime}\left[\mathrm{HDEM}^{-}\right]+2 k_{10}\left[\mathrm{~A}^{-}\right]}\right)\left[\mathrm{A}^{-}\right]\left[\mathrm{H}_{2} \mathrm{DEM}\right]$ 


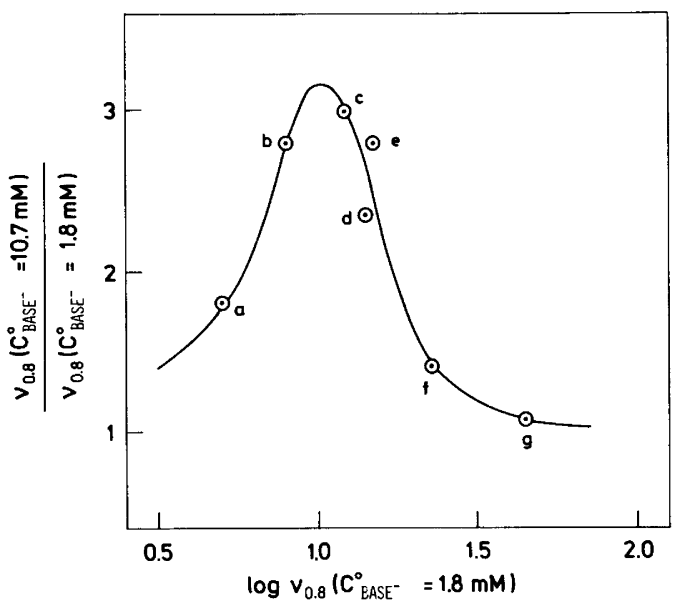

Fig. 1. The BASE ${ }^{-}$acceleration factor, $v_{0.8}\left(C_{\mathrm{BASE}^{-}}^{\circ}=10.7 \mathrm{mM}\right) / v_{0.8}\left(C_{\mathrm{BASE}^{-}}^{\circ}=1.8 \mathrm{mM}\right)$, as a function of the rate of disappearance of $\mathrm{A}^{-}$for $\mathrm{a}$ series of naphthalenes (average of two series of measurements). $C_{\mathrm{A}}^{\circ}=1 \mathrm{mM}, C_{\mathrm{H}_{2} \mathrm{DEM}}^{\circ}=64 \mathrm{mM}$, $t=22^{\circ} \mathrm{C}$. a: Naphthalene, b: 1-Methyl-, c: 2-Methoxy-, d: 2-Methyl-, e: 2,6-Dimethyl-, f: 1-Methoxy- and g: 1,5-Dimethoxy-.

values of the concentrations will be smaller than expected if this equilibrium system is displaced in favor of the products $\mathrm{HDEM}^{-}+\mathrm{HBASE}$. To assure that additional complications were not introduced in this way, we analyzed mixtures of $\mathrm{H}_{2}$ DEM and $\mathrm{Bu}_{4} \mathrm{~N}^{+}, \mathrm{BASE}^{-}$in DMF by ${ }^{13} \mathrm{C}$ NMR spectroscopy and found no evidence of the presence of appreciable amounts of $\mathrm{HDEM}^{-}$and HBASE in the solutions.

In cases where no $\mathrm{BASE}^{-}$is added to the voltammetric solution, the two rate laws (14) and (16) reduce to (19) and (20), respectively. These rate laws show that the protonation of anion radicals of intermediate acidity by $\mathrm{H}_{2}$ DEM are autocatalytic processes and rate data obtained for anion radicals belonging to this class should consequently be interpreted with great care.

The magnitude of the acceleration caused by $\mathrm{BASE}^{-}$was strongly diminished when water was included in the solvent system. The data in the third column of Table 1 were recorded to illustrate this point. Comparison of the data obtained for protonation of 2-methoxynaphthalene anion radical in "dry" DMF (column 2) with those obtained in DMF containing water $\left(C_{\mathrm{H}_{2} \mathrm{O}}^{\circ}=0.5 \mathrm{M}\right.$, column 3) shows that the rate enhancement in going from $C_{\mathrm{BASE}^{-}}^{\circ}=0 \mathrm{mM}$ to $C_{\mathrm{BASE}^{-}}^{\circ}=40.1 \mathrm{mM}$ has been reduced from a factor of 7 to a factor of 2 as a result of the inclusion of water in the solvent. This reduced catalytic effect of $\mathrm{BASE}^{-}$is most likely associated with the formation of hydrogen-bonded complexes between water and BASE $^{-}$which are expected to be less effective as catalysts for the formation of the enol form, $\mathrm{HDEMH}$, than uncomplexed $\mathrm{BASE}^{-}$. The kinetic details of the application of $\mathrm{H}_{2}$ DEM and similar carbon acids as proton sources during protonation of anion radicals in aprotic solvents, as well as the effect of other basic catalysts and the structural consequences of adding water to the solvent system are now being investigated.

\section{Experimental}

The voltammetric instrumentation, data acquisition techniques and solvent and supporting electrolyte purification procedures were the same as recently described. ${ }^{4}$ During DCV experiments, the value of $E_{\mathrm{o}}-E_{\mathrm{sw}}$, where $E_{\mathrm{sw}}$ is the switch potential, was adjusted to $200 \mathrm{mV}$ to minimize the influence of background current caused by reduction of diethyl malonate. The aromatic and heteroaromatic substrates were all reagent grade and used as received. NMR spectra were recorded on a JEOL FX90Q spectrometer. A $10 \%$ solution of diethyl malonate in DMF- $d_{7}$ was used for the estimation of $K_{7}$. The ${ }^{13} \mathrm{C}$ chemical shifts of this solution were the following: $167.3 \mathrm{ppm}$ $(\mathrm{C}=\mathrm{O}), 61.4$ and $41.8 \mathrm{ppm}\left(\mathrm{CH}_{2}\right)$ and $14.1 \mathrm{ppm}$ $\left(\mathrm{CH}_{3}\right)$. These signals were all attributed to the keto form, $\mathrm{H}_{2} \mathrm{DEM}$. No other signals could be detected, allowing for the evaluation of a maximum value of $K_{7}$ equal to $2 \cdot 10^{-3}$.

The apparently straightforward preparation of

$$
\begin{aligned}
& -\mathrm{d}\left[\mathrm{A}^{-}\right] / \mathrm{d} t=2\left(k_{9}+k_{10} \frac{k_{8}^{\prime}\left[\mathrm{HDEM}^{-}\right]}{k_{-8}^{\prime}\left[\mathrm{HDEM}^{-}\right]+2 k_{10}\left[\mathrm{~A}^{-}\right]}\right)\left[\mathrm{A}^{-}\right]\left[\mathrm{H}_{2} \mathrm{DEM}\right] \\
& -\mathrm{d}\left[\mathrm{A}^{-}\right] / \mathrm{d} t=2\left(k_{9}\left[\mathrm{~A}^{-}\right]\left[\mathrm{H}_{2} \mathrm{DEM}^{-}+k_{8}^{\prime}\left[\mathrm{HDEM}^{-}\right]\left[\mathrm{H}_{2} \mathrm{DEM}\right]\right)\right.
\end{aligned}
$$


$\mathrm{Bu}_{+} \mathrm{N}^{+}, \mathrm{HDEM}^{-}$was carried out by mixing equimolar amounts of $\mathrm{Bu}_{4} \mathrm{NOH}$ (titrated $40 \%$ aqueous solution) and diethyl malonate (distilled at reduced pressure) followed by evaporation of the water by a rotary evaporator. A stock solution of the salt was made from the resulting oil by dilution with DMF to a known volume. However, ${ }^{1.3} \mathrm{C}$ NMR spectra of solutions of the salt in DMF$d_{7}$ and dimethyl sulfoxide- $d_{6}$ demonstrated that the product was $\mathrm{Bu}_{4} \mathrm{~N}^{+}, \mathrm{EtOOCCH}_{2} \mathrm{COO}^{-}$formed by hydrolysis of one of the ester groups. The evidence was the following: in addition to signals due to $\mathrm{Bu}_{4} \mathrm{~N}^{+}$, the fully relaxed ${ }^{13} \mathrm{C}$ NMR spectrum in DMF- $d_{\gamma}$ showed five signals of equal intensity at chemical shift values of 170.8 and 167.8 ppm $(\mathrm{C}=\mathrm{O}), 59.5$ and $46.9 \mathrm{ppm}\left(\mathrm{CH}_{2}\right)$ and 14.5 ppm $\left(\mathrm{CH}_{3}\right)$.

Acknowledgements. We wish to thank The Carlsberg Foundation and The Danish Natural Science Research Council for making grants available for purchase of the electrochemical instrumentation and The Carlsberg Foundation for support of M.F.N. Professor Ole Buchardt is acknowledged for gifts of 2,4,6-triphenylpyrimidine and 1,4-diphenylphthalazine $N$-oxide.

\section{References}

1. Amatore, C. and Savéant, J. M. J. Electroanal. Chem. 107 (1980) 353.

2. Amatore, C., Gareil, M. and Savéant, J.M. J. Electroanal. Chem. 147 (1983) 1.

3. Amatore, C. and Savéant, J.M. J. Electroanal. Chem. 86 (1978) 227.

4. Nielsen, M. F., Hammerich, O. and Parker, V. D. Acta Chem. Scand. B 40 (1986) 101.
5. Dietz, R. In: Baizer, M. M. and Lund, H., Eds., Organic Electrochemistry, 2nd ed., Dekker, New York 1983, Chapter 6.

6. Holy, N. L. Chem. Rev. 74 (1974) 243.

7. Borhani, K.J. and Hawley, M.D. J. Electroanal. Chem. IOI (1979) 407.

8. Powell, L. A. and Wightman, R. M. J. Am. Chem. Soc. 101 (1979) 4412.

9. Triebe, F. M., Hawley, M.D. and McDonald, R. N. J. Chem. Soc. Chem. Comm. (1980) 574.

10. Powell, L. A. and Wightman, R. M. J. Electroanal. Chem. 117 (1981) 321.

11. Triebe, F. M. and Hawley, M. D. J. Electroanal. Chem. 125 (1981) 421.

12. Bethell, D. and Parker, V. D. J. Chem. Soc. Perkin Trans. 2 (1982) 841.

13. Mbarak, M. S. and Peters, D. G. J. Org. Chem. 47 (1982) 3397.

14. Herbranson, D. E. and Hawley, M. D. J. Electroanal. Chem. 144 (1983) 423.

15. Shao, R., Cleary, J. A., La Perriere, D. M. and Peters, D. G. J. Org. Chem. 48 (1983) 3289.

16. Nuntnarumit, C.. Null, W. E. and Hawley, M. D. J. Org. Chem. 49 (1984) 4827.

17. Vieira, K. L. and Peters, D. G. J. Electroanal. Chem. 196 (1985) 93.

18. Andersen, M. L. and Hammerich, O. Acta Chem. Scand. B39 (1985) 603.

19. Cheng, S. and Hawley, M. D. J. Org. Chem. 50 (1985) 3388.

20. Ahlberg, E. and Parker, V.D. J. Electroanal. Chem. 121 (1981) 73.

21. Hammerich, O., Svensmark, B. and Parker, V. D. In: Baizer, M. M. and Lund, H., Eds., Organic Electrochemistry 2nd ed., Dekker, New York 1983, Chapter 3.

22. Jones, J. R. and Crooks, J. E. Ann. Rep. Prog. Chem. Sect. C 76 (1979) 131.

23. Jones, J. R. Ann. Rep. Prog. Chem. Sect.C 78 (1981) 137.

24. Toullec, J. Adv. Phys. Org. Chem. 18 (1982) 1.

25. Guthrie, J. P. Can. J. Chem. 57 (1979) 1177.

Received March 14, 1986. 